\title{
THE EFFECT OF BLOWING SNOW ON KATABATIC WINDS IN ANTARCTICA
}

by

\author{
YUJI KODAMA, Gerd WENDLER AND JOAN GOSINK
}

Geophysical Institute, University of Alaska, Fairbanks, Alaska 99701, USA

\section{ABSTRACT}

An acceleration of the katabatic winds during periods of blowing snow was observed in Adelie Land, Antarctica. Data collected by Automatic Weather Stations (AWS) showed a change in the relationship between the katabatic term of the surface geostrophic wind (katabatic force) and the wind speed for periods of blowing snow. When measurements of the katabatic force were plotted against the cube of the wind speed, the slope was steeper for wind speeds at less than a threshold speed for blowing snow. The difference between these two slopes was partly explained by the effect of blowing snow entrained into the atmospheric boundary layer.

\section{INTRODUCTION}

Katabatic winds with blowing snow or blizzards are common phenomena in Adélie Land, Antarctica. There are, however, few experimental or model studies which consider the effect of blowing snow on the katabatic wind, although both blowing snow and katabatic wind have been independently and intensively studied (Ball 1956, Schwerdtfeger 1970, Parish 1982, Loewe 1953, Budd and others 1966, Kobayashi 1972, Schmidt 1982). The only study which combined these two subjects was done by Mather and Miller (1964), who discussed the direction of surface winds in Antarctica with the formation of sastrugi. Ball (1957) and Loewe (1974) mentioned the possible influence of drifting snow on katabatic flow.

In Antarctica the lowest layer of the atmosphere is cooled most of the year by net radiation loss; thus an inverted temperature profile is common. Most of the surfaces are inclined and $97 \%$ of Antarctica is covered by ice and snow. Katabatic wind is a gravity flow maintained by the temperature/density difference of the air in the surface layer when compared with the free air temperature at the same altitude further down the slope. Snow particles entrained into the katabatic flow layer have three possible influences on the characteristics of the boundary flow. 1) increase in density by entrainment, 2) decrease in temperature (i.e. increase in density) by sublimation of snow particles, and 3 ) increase in surface friction. This paper discusses the first two, whereas the third is beyond scope of this study and can be assumed to be negligible (Ball 1957).

\section{INSTRUMENTATION AND DATA}

Five Automatic Weather Stations (AWS) were installed on the sector of Adélie Land in the Antarctic Continent: four on the slope (Wendler and Poggi 1981) and another at the top of an ice dome, Dome C (Wendler and Kodama 1984) (Figure 1). They extended over a distance of $1080 \mathrm{~km}$ with an altitude difference of $3000 \mathrm{~m}$. Geographical settings are given in Table 1. Data collected by the AWS (temperature, atmospheric pressure, wind speed and direction) are transmitted via satellites as part of the Argos system (Poggi and others 1982, Stearns and Savage 1981). Since the frequency of observation depends on the availibility of satellites, the hourly data were constructed by the

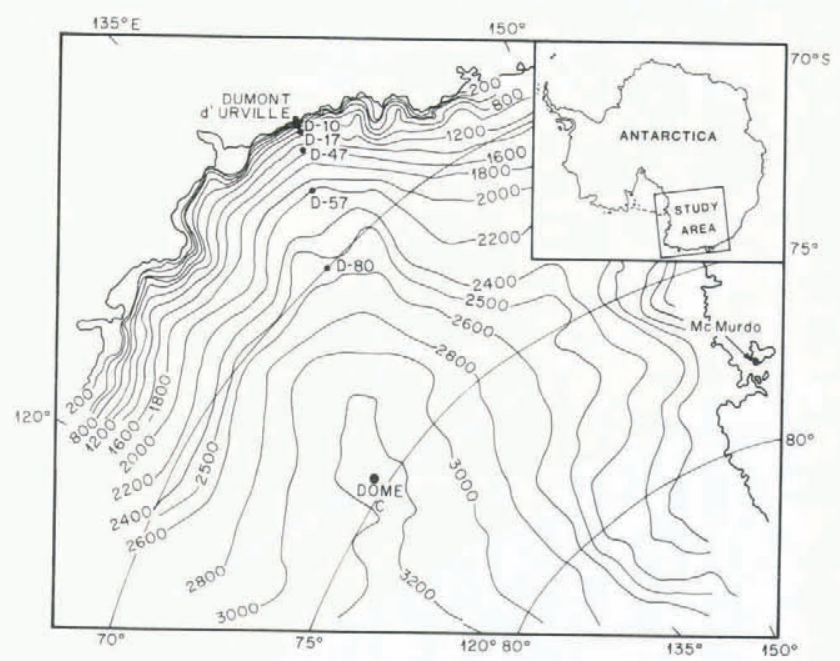

Fig.1. Locations of Automatic Weather Stations and topography in Adélie Land, Antarctica.

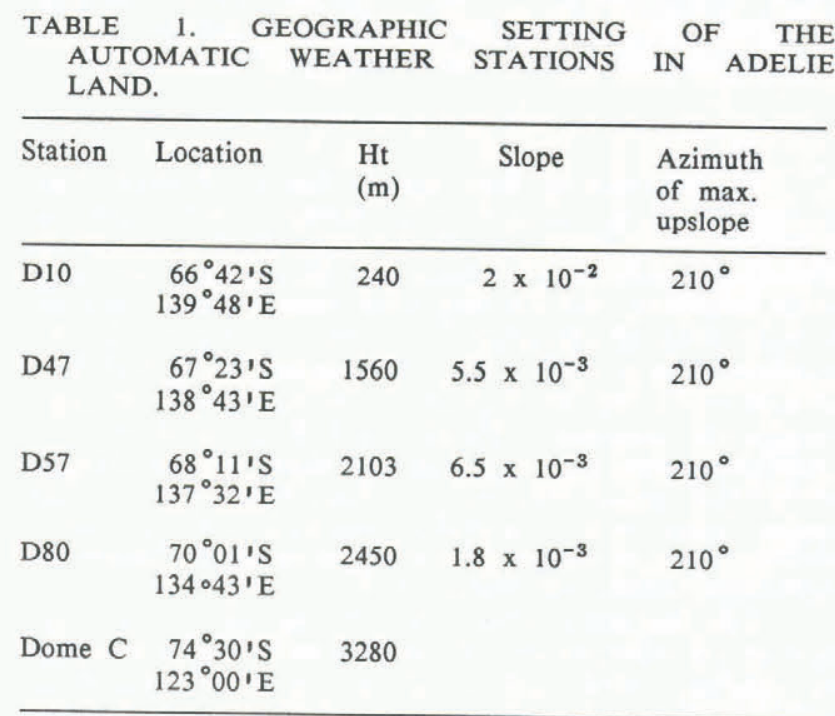

observation closest to the hour. The rate of recovery for the hourly data was more than $90 \%$. Data used here are for the period from 1 June to 10 July in 1983 at stations D80, D47 and D10, located approximately on a line between Dome $C$ and Dumont d'Urville. The direction of this line ( 210 degrees from true north) is also the direction of maximum slope. Sensors on the AWS stand approximately three meters above the ground. 
KATABATIC FORCE AND BLOWING SNOW DENSITY

The structure of the atmospheric boundary layer is considerably modified by slope of the terrain (Sorbjan 1983). The presence of an inversion layer over sloping terrain generates an additional horizontal pressure gradient force, called "katabatic force" after Ball (1956) due to horizontal temperature differences. Details are given in Figure 2.

$$
\begin{aligned}
& p_{1}=p_{3}+\rho_{2} g \Delta z \\
& p_{2}=p_{4}+\rho_{1} g \Delta z \\
& p_{2}-p_{1}=\left(p_{4}-p_{3}\right)+\left(\rho_{1}-\rho_{2}\right) g \Delta z \\
& -\frac{1 \Delta p}{\rho_{1} \Delta x}=-\frac{1}{\rho_{1}}\left[\frac{p_{4}-p_{3}}{\Delta x}\right]-g\left[\frac{\rho-\rho_{2}}{\rho_{1}}\right] \frac{\Delta z}{\Delta x} \\
& {\left[-\frac{1}{\rho_{1}} \frac{\partial p}{\partial x}\right]=-\left[\frac{1 \partial p}{\rho_{1} \partial x}\right]-g \frac{\Delta T}{T}\left[\frac{\partial z}{\partial x}\right]}
\end{aligned}
$$

$\begin{array}{lll}\text { inversion } & \text { above } & \text { sloped } \\ \text { layer } & \text { inversion } & \text { inversion } \\ \text { force }\end{array}$

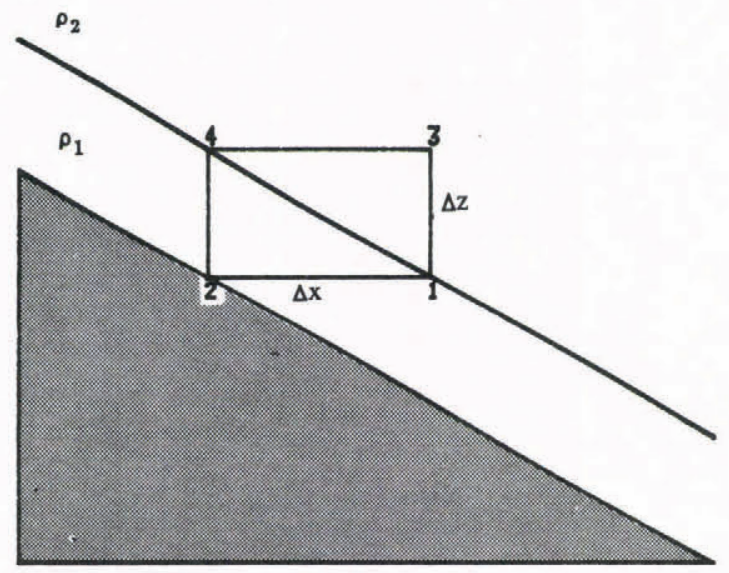

Fig.2. Sloped-inversion pressure gradient force. Inversion strength and terrain slope determine magnitude of the horizontal gradient force. After Parish (1980).

The increase in flow density due to blowing snow is equivalent to an additional cooling, and therefore, increases the katabatic force. Figure 3 shows the equivalent amount of cooling due to the blowing snow with respect to the blowing snow density. For example, a snow load of $10 \mathrm{~g} / \mathrm{m}^{3}$ means an increase of density equivalent to a cooling of $2^{\circ} \mathrm{C}$ (Loewe 1974), which is equivalent to the average inversion strength in summer months in Antarctica (Phillpot and Zillman 1970). The cooling becomes important for the blowing snow density of a few grams per cubic meter. This density and higher ones were frequently observed for the wind speeds above $18 \mathrm{~m} / \mathrm{s}$ at $10 \mathrm{~m}$ level at Byrd Station in Antarctica (Budd and others 1966).

The increased density in the katabatic flow layer due to the entrainment of blowing snow particles leads to stronger wind speeds as the result of increased katabatic force. Temperature and atmospheric pressure are, however, not directly affected by the entrained snow particles. This is one of the main reasons why the study of blowing snow is difficult. The katabatic force, $\mathrm{KF}$, in case of blowing snow can be expressed in the following form:

$$
\mathrm{KF}=\mathrm{KF}_{\mathrm{a}}+\mathrm{KF}_{\mathrm{bs}}
$$

where $\mathrm{KF}_{\mathrm{a}}=\mathrm{g}\left(\theta_{\mathrm{f}}-\theta_{\mathrm{g}}\right) \alpha \sqrt{\theta}, \mathrm{KF}_{\mathrm{bs}}=g \rho_{\mathrm{bs}} \alpha \sqrt{\rho}$. KF is the katabatic force in the case without blowing snow and $\mathrm{KF}_{\mathrm{bs}}$ is an additional force due to blowing snow. $\mathrm{g}$ and

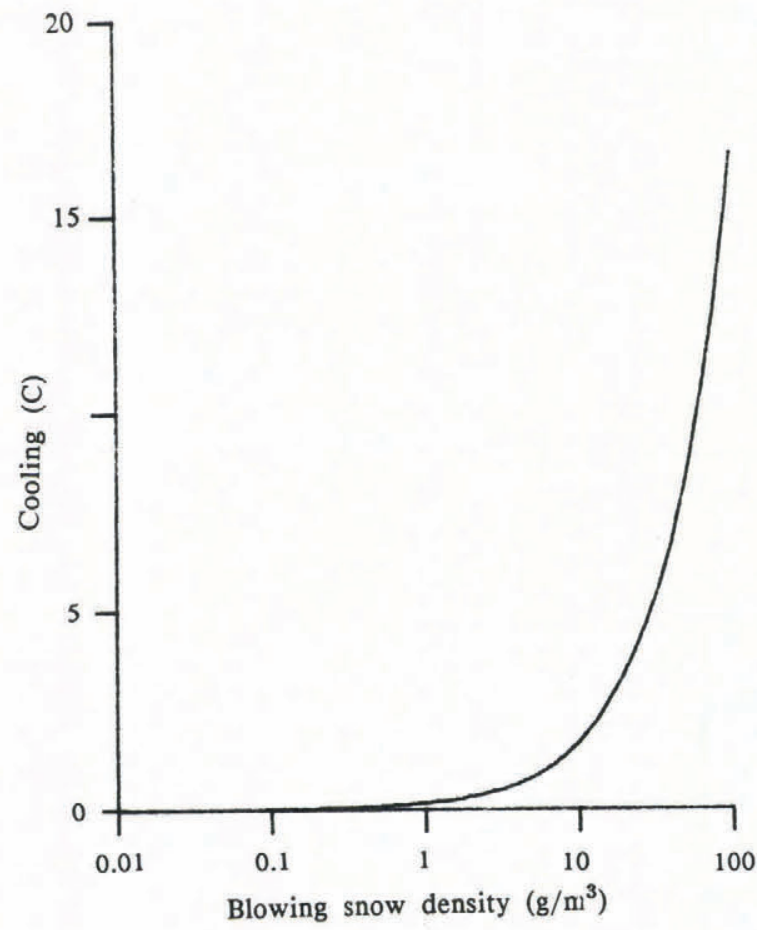

Fig.3. Equivalent cooling by density increase due to blowing snow, and blowing snow density. Curve calculated for surface temperature $-20^{\circ} \mathrm{C}$ and inversion strength $10^{\circ} \mathrm{C}$.

$\alpha$ are respectively gravitational acceleration and slope of terrain. $\rho$ and $\theta$ are density and potential temperature respectively. The subscripts $s$, bs, and $f$ indicate surface, blowing snow and free atmosphere. The bar denotes the average through the layer. $\mathrm{KF}_{\mathrm{bs}}$ cannot be calculated from the temperature and pressure because these two parameters are not directly changed by blowing snow.

According to the slab model of katabatic wind (Ball 1956), wind speed is proportional to the cube root of katabatic force, i.e.:

$$
\mathrm{V}^{3}=(\mathrm{KF}) \mathrm{Q} / \mathrm{k}
$$

where $Q=u h$ expresses net downslope tranport of the medium, and where $u, h$ and $k$ are, respectively, downslope components of wind speed, depth of katabatic flow and friction coefficient. For this derivation Ball assumed 1) nelgigible synoptic pressure gradient and 2) quadratic shear stress. Since the effect of snow particles entrained into the flow does not affect the values of temperature and pressure, $\mathrm{KF}_{\mathrm{a}}$ in case of blowing snow becomes:

$$
\mathrm{KF}_{\mathrm{a}}=\mathrm{kV}^{3} / \mathrm{Q}-\mathrm{KF}_{\mathrm{b}}
$$

The transport rate of snow by wind, $\rho_{b s} Q$, is proportional to the cube of wind speed (Kobayashi 1972, Dyunin 1967). Since $\mathrm{KF}_{\mathrm{bs}}$ is proportional to $\rho_{\mathrm{bs}}, \mathrm{KF}_{\mathrm{bs}}$ is as a result proportional to $\mathrm{V}^{3} / \mathrm{Q}$. Thus, from the equation (3) it follows:

$$
K F_{\mathrm{a}}=(\mathrm{k}-\mathrm{c}) \mathrm{V}^{3} / \mathrm{Q}
$$

where $c$ is a constant. The slope of the relationship of $\mathrm{KF}_{\mathrm{a}}$ and $\mathrm{V}^{3}$ is expected to be smaller for the case of blowing snow.

\section{KATABATIC FORCE AND ALTIMETER CORRECTION METHOD}

AWS collect only surface data, whereas information on the free atmosphere is needed to estimate the katabatic force. Therefore, the altimeter correction method, which is frequently used to estimate the surface 
geostrophic wind (Bonner and Paegle 1970; Pinty and Isaka 1982), was introduced. The katabatic force normal to isoheight of the sloped terrain, $\mathrm{KF}_{\mathrm{a}}$, can be expressed in the following form:

$$
\mathrm{KF}_{\mathrm{a}}=\mathrm{gS}^{*} \alpha
$$

where $\mathrm{S}^{*}=\left(\mathrm{T}_{\mathrm{s}}-\mathrm{T}_{\mathrm{sp}}\right) / \mathrm{T}_{\mathrm{sp}} \cdot \mathrm{T}_{\mathrm{s}}$ is virtual temperature at terrain surface. $T_{\mathrm{sp}}^{\mathrm{sp}}$ represents temperature in the atmosphere corresponding to the station

\section{RESULT}

In Figure 4, $\mathrm{KF}_{\mathrm{a}}$ is plotted against the cube of wind speed for D47. The solid circles indicate averages for wind speed intervals of $2 \mathrm{~m} / \mathrm{s}$. The length of line attached to each circle gives twice the standard deviation. The numerical values above the abscissa give the numbers of the observations for the interval. Two linear regression lines are drawn using the lower six points and the upper five points. It is obvious from Figure 4 that the slope for weaker wind speeds is steeper than that for stronger wind speeds. This may indicate the effect of blowing snow, as the stronger wind speeds, which reflect the effect of blowing snow, are increased with the relatively small increase in KF which does not take account of the effect of blowing snow. The wind speed at the terminal point of two regression lines $(12.4 \mathrm{~m} / \mathrm{s})$ agrees quite well with the wind speed at which blowing snow density can be more than $1 \mathrm{~g} / \mathrm{m}^{3}$ according to Budd and others (1966) and our own observations in Adélie Land.

In order to test whether the increase in wind velocity which occurs at wind speeds stronger that 12.4 $\mathrm{m} / \mathrm{s}$ could be due to the increased density of the air with the entrained blowing snow, we compare the measured intensification of the wind with the theoretical intensification of the wind due to entrained blowing snow. $\mathrm{KF}_{\mathrm{bs}}$ is defined by Equation 3 and appears in Figure 4 as the difference between the two regression

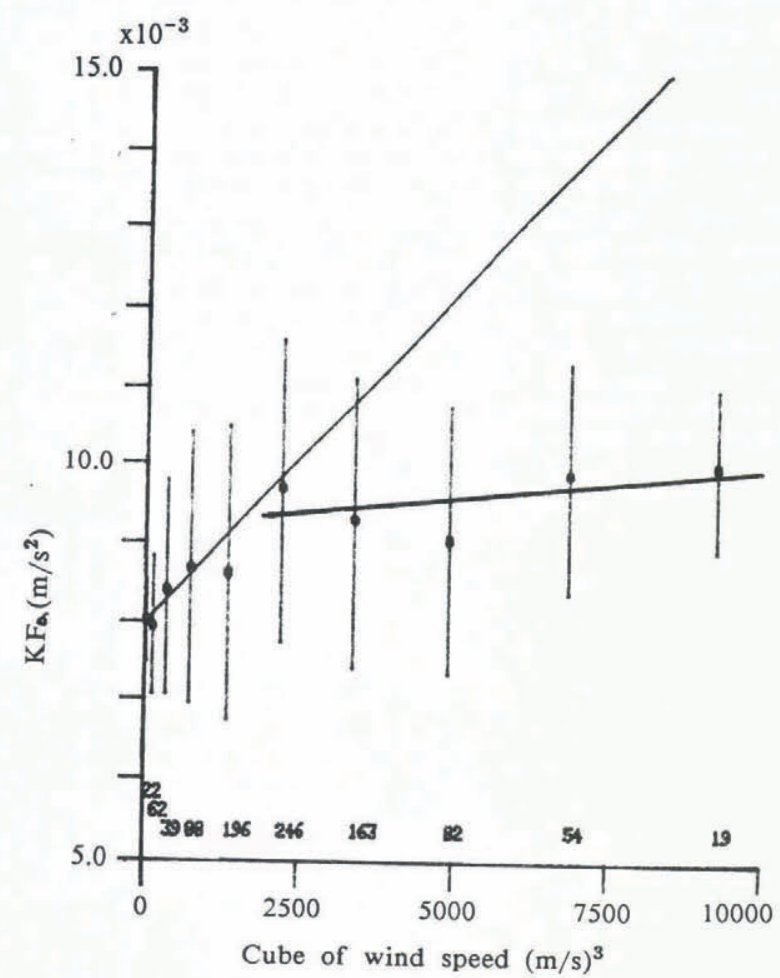

Fig.4. Katabatic force and wind speed. Dots show averages for wind speed intervals of $2 \mathrm{~m} / \mathrm{s}$ : lines give $2 x$ the standard deviation. Numbers above the abscissa give numbers of observations. Two linear regression lines were drawn using lower six points and upper five points. lines; $\mathrm{KF}_{\mathrm{bs}}$, which is calculated as the difference in the two regression lines in Figure 4 for wind speeds stronger than $12.4 \mathrm{~m} / \mathrm{s}$, is plotted against wind speed (solid line in Figure 5). The ordinate on the right of the figure is the amount of suspended snow required to explain the total increase of wind speed. This ordinate may be determined from Figure 3. For wind speed of 18 $\mathrm{m} / \mathrm{s}$, for example, $39 \mathrm{~g} / \mathrm{m}^{3}$ of suspended snow would be required. However, according to Budd and others (1966), the amount of suspended snow particles is about one third of this value. A realistic amount of suspended snow as a function of wind speed is also given in Figure 5 (broken line). Hence, there must be an additional accelerative force.

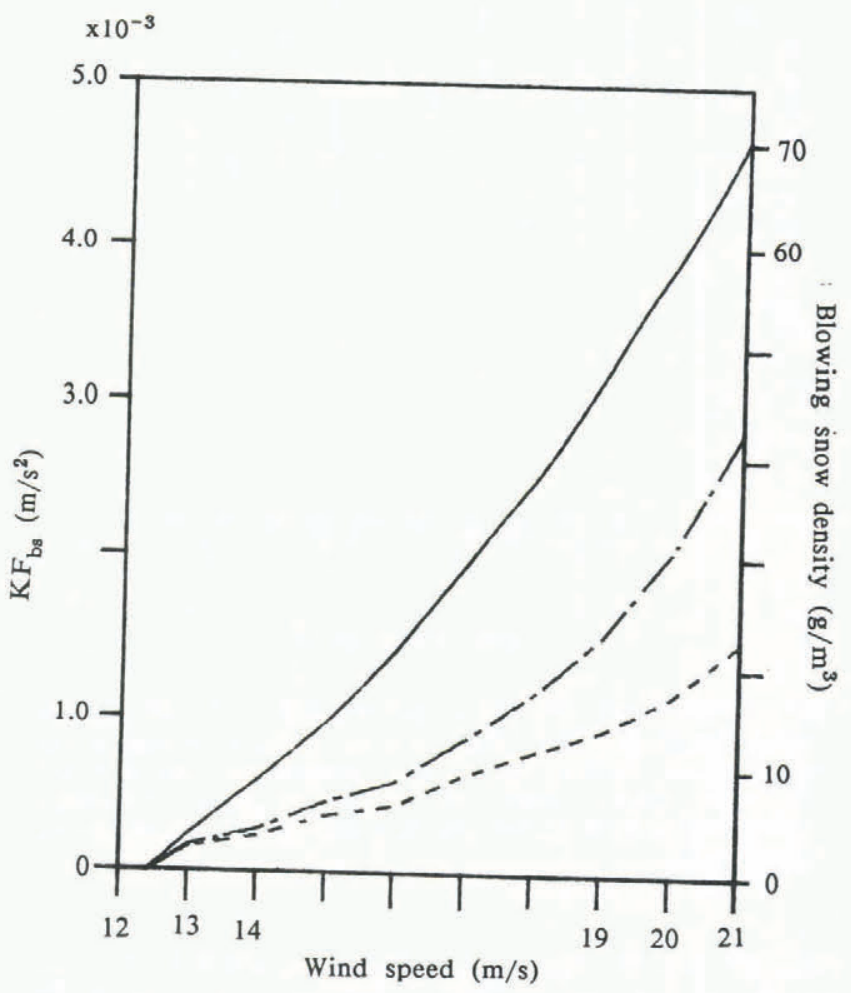

Fig.5. $\mathrm{KF}_{\mathrm{bs}}$ and wind speed. The right-hand ordinate: density of suspended snow required to explain the increase of wind speed. Solid line: $\mathrm{KF}_{\mathrm{bg}}$. Pecked line: blowing snow density at $3 \mathrm{~m}$ for corresponding wind speed (Budd and others 1966). Broken line: total effect of blowing snow including sublimation from the suspended snow particles.

A candidate to fill the gap is the additional cooling due to sublimation from blowing snow particles. Sublimation from blowing snow particles occurs due to the difference in vapor pressures at the surface of snow particles and the ambient air. It is difficult to achieve an accurate estimate of sublimation without knowledge of moisture in the katabatic flow. However, a rough estimation was done by assuming the following conditions: 1) The air is kept saturated with respect to ice; 2) Flow is downslope and stationary; 3) Sublimation occurs due to temperature increase by compression-warming during descent; 4) Time for travel of air parcel is fixed to a time scale of gravity flow $\mathrm{Tg}=\mathrm{U} \theta / \mathrm{g}\left(\theta_{\mathrm{f}}-\Theta_{\mathrm{g}}\right) \propto($ after Gosink 1983), so that the distance of descent depends on the wind speed; and 5) The average sublimation of the whole layer is proportional to the depth of the blowing snow layer with densities of more than $1 \mathrm{~g} / \mathrm{m}^{3}$. Estimated cooling under these conditions is converted to the equivalent blowing snow density and added to Figure 5. This effect adds another $20-30 \%$ to the katabatic force. Hence, suspended snow and sublimation of the snow particles can explain about two thirds of $\mathrm{KF}_{\mathrm{bs}}$. Complete 
agreement can not be expected due to inaccuracies in the assumed amount of suspended snow and the rate of sublimation from the snow particles. Furthermore the model does not totally represent nature

In Figure 6, temperature differences between D80 and D47 are plotted against wind speeds at D47. At

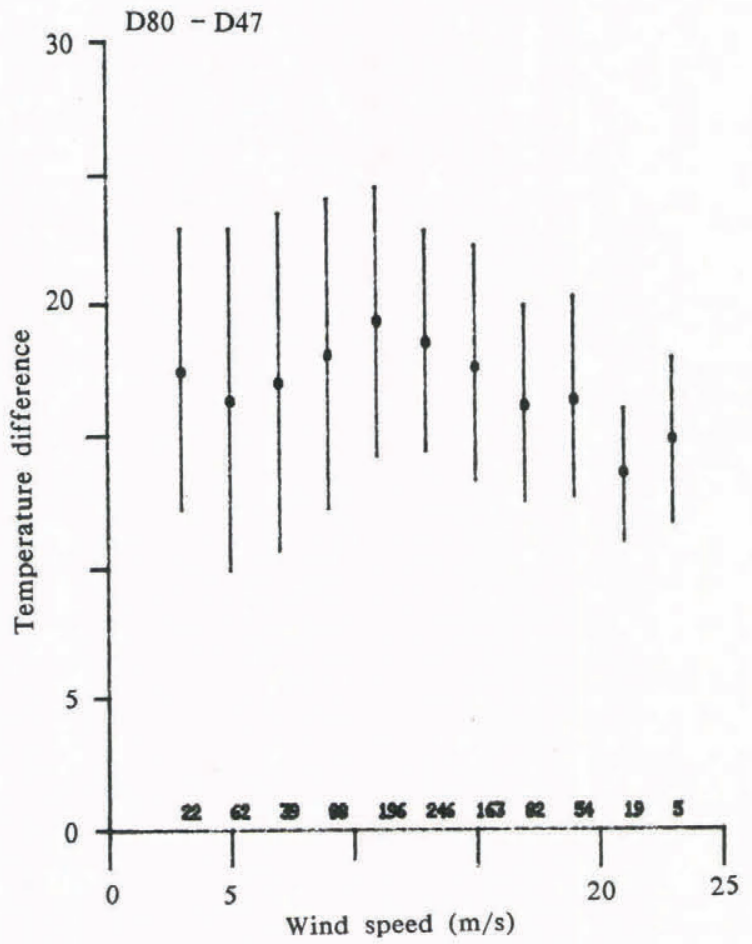

Fig.6. Temperature difference between D80 and D47 against wind speed at D47. Solid circles indicate averages for wind speed intervals of $2 \mathrm{~m} / \mathrm{s}$. Length of line attached to each circle gives twice the standard deviation. Numerical values above the abscissa are the number of observations.

about $11 \mathrm{~m} / \mathrm{s}$ the relationship changes drastically. $11 \mathrm{~m} / \mathrm{s}$ appears to be the threshold wind speed at which the sublimation of blowing snow starts to contribute substantially to the katabatic flow. The decreased temperature difference provides additional observational evidence of cooling caused by sublimation of the suspended snow at D47.

\section{SUMMARY}

The effect of blowing snow on katabatic wind was investigated. Blowing snow densities of more than a few grams per cubic meter substantially affect the katabatic force. The sublimation of blowing snow particles is also an important factor for maintaining the katabatic force. Further intensive measurements of katabatic flow, especially of moisture, are needed to study the effect of blowing snow on the katabatic wind.

\section{ACKNOWLEDGEMENTS}

This research is supported by NSF grant DPP-8100-161. Special thanks go to Dr G. Weller for his valuable comments.

\section{REFERENCES}

Ball F K 1956 The theory of strong katabatic winds. Australian Journal of Physics 9(3): 373-386

Ball F K 1957 The katabatic winds of Adelie Land and King George V Land. Tellus 9(2): 201-208

Budd W F, Dingle W R J, Radok U 1966 The Byrd snow drift project: outline and basic results. In Rubin M J (ed) Studies in Antarctic Meteorology. Washington, D.C. American Geophysical Union: 71-134
Bonner W D, Paegle J 1970 Diurnal variations in boundary layer winds over the south-central United States in summer. Monthly Weather Review 98(10): 735-744

Dyunin A K 1967 Fundamentals of the mechanics of snow storms. In Oura $\mathrm{H}(e d)$ Physics of Snow and Ice, Institute of Low Temperature Science, Sapporo, Japan 1(2): 1065-1073

Gosink J P 1981 A review of some models of katabatic flow. Geophysical Institute Report, University of Alaska, UAG R-282: 1-34

Kobayashi D 1972 Studies of snow transport in low-level drifting snow. Contributions from the Institute of Low Temperature Science, A, 24: 1-58

Loewe F 1953 Glaciological work in Terre Adelie in 1951, preliminary report. Journal of Glaciology 12: $248-249$

Loewe F 1974 Considerations concerning the winds of Adelie Land. Zeitschrift fur Gletscherkunde und Glazialgeologie, 10: 189-197

Mather K B, Miller G S 1967 Notes on topographic factors affecting the surface wind in Antarctica, with special reference to katabatic winds: and bibliography. Technical Report GA-900, Geophysical Institute, University of Alaska

Parish T R 1980 Surface winds in East Antarctica. PhD Thesis, University of Wisconsin

Parish T R 1982 Surface air flow over East Antarctica. Monthly Weather Review 110: 84-90

Philpot H R, Zillman J W 1970 The surface temperature inversion over the Antarctic Continent. Journal of Geophysical Research 75(21): 4161-4169

Pinty B, Isaka H 1982 Analysis of the diurnal oscillation of surface geostrophic wind over Western Europe. Tellus 34: 545-554

Poggi A, Delaunary D, Hallot H, Wendler G 1982 Interactions atmospheric-glace-ocean en Antarctique de l'Est. In (ed) Proceedings of the Argos users conference, Paris, April 20-21: 103-111

Schmidt R A 1982 Vertical profiles of wind speed, snow concentration, and humidity in blowing snow. Boundary Layer Meteorology 23: 223-246

Schwerdtfeger W 1970 The climate of the Antarctic. In Landsberg H E (ed) World Survey of Climatology Orvig S ed Chap IV, vol XIV: 253-355. Amsterdam, Elsevier

Sorbjan Z 1983 Rossby number similarity in the atmospheric boundary layer over slightly inclined terrain. Journal of the Atmospheric Sciences 40: 718-728

Stearns C, Savage M 1981 Automatic weather stations, 1980-1981. Antarctic Journal of the United States, 1981 Review, 16(5): 190-192

Wendler G, Kodama Y 1984 On the climate of Dome $C$, in relation to its geographical setting. Journal of Climatology 4: 495-508

Wendler G, Poggi A 1980 Measurement of the katabatic wind in Antarctica. Antarctic Journal of the United States, 1980 Review 15(5): 193-195 